\title{
A LEGITIMIDADE DO PODER POLÍTICO SOB O PONTO DE VISTA JURÍDICO EM GOVERNOS DEMOCRÁTICOS
}

\author{
Ivanaldo Pereira $^{1}$
}

\begin{abstract}
Resumo:
No artigo A legitimidade do poder políticos sob o ponto de vista jurídico em governos democráticos discutir-se-á a legitimação do poder político perante a ordem jurídica na qual está inserido este poder em governos democráticos, expondo o binômio política-direito e confrontando opiniões de pensadores, cientistas políticos e juristas sobre o assunto. Será colocado em debate se o poder político é algo que antecede ou transcende a esfera jurídica, tendo sua origem e disseminação a partir de relações sociais e políticas. Em seguida argumentar-se-á que, para esse poder político originado de relações sociais e políticas sobreviver, faz-se mister legitimá-lo e ampará-lo posteriormente através de instituições jurídicas, ensejando que, apesar de o poder político nascer de relações sócio-políticas, sua perpetuação dependeria de um posterior supedâneo jurídico, acarretando que, sem o amparo de instituições jurídicas, o poder político, em democracias, não é legítimo, haja vista que o poder político sem o devido respaldo jurídico não é suficiente para a legitimação deste poder, a não ser que seja ditatorial ou autoritário.
\end{abstract}

\section{Introdução}

Preliminarmente, importa ressaltar que foi somente com Max Weber que o tema "legitimidade" passou a ter sua relevância reconhecida no campo da Teoria Política $^{2}$. De acordo com Weber, deve-se ter uma concepção realista da política (contrapondo-se à visão meramente ideológica), perfilhando essa característica, entre outras, que a política é o campo das relações de poder, onde os diversos grupos humanos digladiam-se por sua obtenção na dúplice forma - poder de fato e poder legítimo ${ }^{3}$.

Fundamentada nesta concepção realista de política, a própria definição weberiana de Estado pode ser entendida como o "monopólio da força legítima", consagrando sociologicamente a definição de Estado em função da utilização de um meio, qual seja, a força física. Cita-se a elocução de Trotski em Brest-Litovsk, (Bobbio, 2000: 133), que veementemente afirma que "todo Estado está fundado na força". E o próprio Bobbio corrobora dizendo que "e, na verdade, é justo que assim seja. Se houvesse apenas organismos nos quais fosse ignorada a força como meio, o conceito de 'Estado' desapareceria e em seu lugar entraria aquilo que, no sentido particular da palavra, poderia ser chamado de 'anarquia"'.

\footnotetext{
${ }^{1}$ Ivanaldo Pereira é mestrando em Direito pela Universidade Católica de Brasília, funcionário da Previdência Social. Trabalho elaborado sob a orientação da $\operatorname{Prof}^{a}$ Dr $^{a}$ Leila Bijos.

${ }^{2}$ BOBBIO, Norberto. Teoria Geral da Política, 8 a tiragem, Rio de Janeiro: Editora Campus, 2000, p.130.

${ }^{3}$ BOBBIO, Norberto. Op. Cit., p. 132.

${ }^{4}$ FREUND, Julien. Sociologia de Max Weber, $5^{\text {a }}$. ed., Rio de Janeiro: Forense Universitária, 2000, p. 161.
} 
Para Weber todas as estruturas políticas usam a força, mas diferem no modo e na extensão como a empregam ou ameaçam empregar contra outras organizações políticas. Por este entendimento, apreende-se que o que verdadeiramente está por trás da obtenção do poder é o uso da força, sendo vista a legitimidade deste poder adquirido como sendo a legitimidade da força empregada para obtê-10 ${ }^{5}$.

Confirmando esta acepção weberiana de estado e poder, Althusser entende o Estado como uma força de execução e de intervenção repressiva a serviço das classes dominantes, e demonstra uma variante deste poder repressivo, denominando-o de aparelhos ideológicos do estado, confundindo-se estes com aquele ${ }^{6}$.

Mas este uso da força, para Gérard Lebrun (1999), não significa necessariamente a posse de meios violentos conforme preconizado por Althusser. Pode ser também o uso de outros meios capazes de influenciar o comportamento das pessoas, como por exemplo, a força dos partidos políticos ${ }^{7}$.

Hodiernamente, salvo raras exceções, ao se falar de formas de obtenção de poder sob o manto de instituições jurídicas pré-definidas, não é possível se esquivar da figura do constitucionalismo positivado. Sobre isso, veja-se a lição de Alexandre de Moraes:

"A origem formal do constitucionalismo está ligada às Constituições escritas e rígidas dos Estados Unidos da América, em 1787, após a Independência das 13 colônias, e da França, em 1791, a partir da Revolução Francesa, apresentando dois traços marcantes: organização do Estado e limitação do poder estatal, (...).

Tem, pois, por objeto a constituição política do Estado, no sentido amplo de estabelecer sua estrutura, a organização de suas instituições e órgãos, o modo de aquisição e limitação do poder, $(. . .)^{8}$.

Neste mesmo sentido, enuncia, também, Jorge Miranda (1990, apud Moraes, 2006: 1), definindo-o como "a parcela da ordem jurídica que rege o próprio Estado, enquanto comunidade e enquanto poder".

Sobre o tema, Hans Kelsen, em Teoria Pura do Direito, defende a inevitabilidade de se conceber o Estado, como uma ordem de conduta humana. Ele aponta que é usual conceber o Estado como uma organização política, acarretando a consequiência de ser o Estado uma ordem de coações, cada indivíduo coagindo o outro. Dessa forma, a

\footnotetext{
${ }^{5}$ FREUND, Julien. Op. Cit.

${ }^{6}$ Notas de aula da Dra. Leila Bijos, Disciplina Política Internacional, Universidade Católica de Brasília, Curso de Mestrado Strictu Senso em Direito, $1^{\circ}$ semestre de 2006.

${ }^{7}$ Idem.

${ }^{8}$ MORAES, Alexandre de. Direito Constitucional, 19ª ed., São Paulo: Atlas, 2006, p. 1.
} 
ordem jurídica teria o papel de ligar estes atos reciprocamente coativos aos seus pressupostos $^{9}$. uma ordem jurídica ${ }^{10}$

Para Kelsen, o Estado visto como organização política é necessariamente

Diante disso, ao se ter o Estado como uma ordem jurídica, e, modernamente, em sua grande maioria, positivados constitucionalmente, a forma de obtenção do poder já vem previamente definida na constituição. Há de se considerar que o poder político já nasce carente de legitimação jurídica, ou mesmo, já nasce imerso em uma ordem que dita seus limites de atuação. Isto fica ainda mais claro nos Estados democráticos, onde a democracia requer constantemente que atos políticos sejam eivados de legitimidade jurídica.

Ademais, para que haja o efetivo respeito à democracia, é necessário que o processo democrático da política inclua mecanismos que possibilitem a assimilação de suas decisões. Seria democrática e legítima a decisão supostamente possível de ser aceita. Desta forma, seria legítima a decisão em que se pode supor que um terceiro espere que os demais atingidos pela decisão também a aceitem ${ }^{1}$.

Este também é o entendimento de Benjamin Zymler, ao analisar Luhman, e argumentar que "um dos pontos marcantes da teoria desenvolvida por Luhmann refere-se à questão da legitimidade do direito, visto como, o "convencimento fatual da validade do direito ou dos princípios e valores nos quais as decisões vinculativas se baseiam". Para o sociólogo alemão, legitimidade não seria um dado ou um valor apriorístico. Propõe uma noção de legitimidade dissociada da fundamentação metafísica, ontológica ou axiológica. Dá um sentido procedimental ao conceito ao expressá-lo como legitimação, entendido como o mecanismo por meio do qual as pessoas se mostram inclinadas a acatar e respeitar as decisões jurídicas ${ }^{12}$.

A contextualização de Zymler e Luhmann, nos leva à conclusão de que a natureza do sistema jurídico está implícita num subsistema do sistema político, havendo uma superposição deste sobre aquele, no sentido de que o direito serve para instrumentalizar a ação política ${ }^{13}$.

A política é, de fato, a ciência que fornece ao direito a orientação para a tomada de decisões, tanto como é quem concede efetividade aos meios de coerção estatal

\footnotetext{
${ }^{9}$ KELSEN, Hans. Teoria Pura do Direito, [Tradução João Baptista Machado], $6{ }^{\text {a }}$ ed., São Paulo: Martins Fontes, 1998, p. 316.

${ }^{10}$ KELSEN, Hans. Op. Cit., p. 317.

${ }^{11}$ LUHMANN, Niklas. Sociologia do Direito II, Rio de Janeiro: Edições Tempo Brasileiro, 1985, p. 64.

${ }^{12}$ ZYMLER, Benjamin. Política e Direito: Uma Visão Autopoiética, $1^{\mathrm{a}}$. ed. $2^{\mathrm{a}}$. tiragem, Curitiba: Juruá, 2003, p. 105.

${ }^{13}$ CAMPILONGO, Celso Fernandes. Política, Sistema Jurídico e Decisão Judicial, São Paulo: Max Limonad, 2002, p. 93.
} 
para efetivação da justiça, fixando uma dependência do sistema jurídico em relação ao político $^{14}$.

Este é, também, o entendimento de Paulo Bonavides que depreende que "toda a legitimidade em matéria constitucional é mais política que jurídica". Para ele, a legitimidade tem por base princípios como "o espírito, a razão, a consciência da Constituição, o alfa e ômega de toda lei fundamental, o sentimento profundo de cidadania, que a faz intangível e inquebrantável"15.

$\mathrm{Na}$ verdade, isto não quer dizer que o poder político não necessite do aparato jurídico para ter seus atos legitimados, mesmo que também represente a vontade deste mesmo poder político, pois, uma vez delimitados os contornos da expressão do poder estatal político sob o ponto de vista sociológico, deve-se considerar que este "poder político" oriundo de relações sociais (povo e grupos políticos), exerce sua capacidade de mando dentro de uma ordem jurídica pré-existente em se tratando de governos democráticos de direito. Esta ordem jurídica rege estas mesmas relações sociais que instituíram o poder de fato, e, somente com a instauração de instituições jurídicas voltadas a esse fim, é que se pode falar em legitimidade do poder, acarretando a transmudação de sua natureza que originalmente era de poder de fato (político) para poder legítimo, entendido tal como sendo o poder político-jurídico. Ou seja, o poder legítimo seria a permanência do poder político após passar pelo crivo das instituições jurídicas, que não podem e não devem guardar interesses próprios do poder político, sob pena de descaracterizar o princípio da separação dos poderes, incorrendo em uma promiscuidade de poderes.

\footnotetext{
${ }^{14}$ CAMPILONGO, Op. Cit.

${ }^{15}$ BONAVIDES, Paulo. Ciência Política, 10ª edição, São Paulo: Malheiros Editores Ltda, 2003.
} 


\section{BIBLIOGRAFIA:}

ALTHUSSER, Louis. Aparelhos Ideológicos de Estado, 3ª ed., Rio de Janeiro: Graal, 1987.

BOBBIO, Norberto. Teoria Geral da Política, $8^{\mathrm{a}}$ tiragem, Rio de Janeiro: Editora Campus, 2000.

BONAVIDES, Paulo. Ciência Política, 10ª . ed., São Paulo: Malheiros Editores Ltda, 2003.

CAMPILONGO, Celso Fernandes. Política, Sistema Jurídico e Decisão Judicial, São Paulo: Max Limonad, 2002.

FREUND, Julien. Sociologia de Max Weber, $5^{\text {a }}$ ed., Rio de Janeiro: Forense Universitária, 2000.

KELSEN, Hans. Teoria Pura do Direito. [Tradução João Baptista Machado], $6^{a}$ ed., São Paulo: Martins Fontes, 1998.

LEBRUN, Gérard. O que é Poder?, $5^{\mathrm{a}}$ reimpressão da $14^{\mathrm{a}}$ edição, São Paulo: Ed. Brasiliense, 2004.

LUHMANN, Niklas. Sociologia do Direito II, Rio de Janeiro: Edições Tempo Brasileiro. 1985.

MORAES, Alexandre de. Direito Constitucional, 19ª ed., São Paulo: Atlas, 2006.

ZYMLER, Benjamin. Política e Direito: Uma Visão Autopoiética, $1^{\text {a }}$. ed., $2^{\text {a }}$. tiragem, Curitiba: Juruá, 2003. 